\title{
A Survey on Smart Agricultural System Using LoRa Wireless Technology
}

\author{
Parimal Solanki ${ }^{1}$ | Dr. Dipak M Patel ${ }^{2}$ | Dr. Darshak G Thakore \\ ${ }^{1}$ PG Student, Computer Engineering, Birla Vishvakarma Mahavidyalaya, Vallabh Vidyanagar, Anand, Gujarat, India. \\ 2Professor, Electronics Engineering, Birla Vishvakarma Mahavidyalaya, Vallabh Vidyanagar, Anand, Gujarat, India. \\ ${ }^{3}$ Professor \& Head, Computer Engineering, Birla Vishvakarma Mahavidyalaya, Vallabh Vidyanagar, Anand, Gujarat, India.
}

To Cite this Article

Parimal Solanki, Dr. Dipak M Patel and Dr. Darshak G Thakore, "A Survey on Smart Agricultural System Using LoRa Wireless Technology", International Journal for Modern Trends in Science and Technology, Vol. 06, Issue 05, May 2020, pp.:13-18; https://doi.org/10.46501/IJMTST060503

Article Info

Received on 24-March-2020, Revised on 20-April-2020, Accepted on 25-April-2020, Published on 29-April-2020.

\section{ABSTRACT}

Over the past few years, the designing in smart agriculture system is a very important concept. Using smart farming techniques we can build up the crop yield, and concurrently attain better output from the input. In precision agriculture, a wireless sensor network brings a cost-effective solution to watch and manipulate. We already have many wireless protocols like Wi-Fi, Cellular, BLE (Bluetooth low energy), etc. Although this automation, not optimal for cultivation sensor nodes, there is a demand to send information to a great distance without an internet connection. This leads to boost the LoRa (Long range) technology, which can do very long-range transmission with the lowest cost [14]. The paper provides a brief survey of certain requirements for Smart Agriculture such as wireless sensor networks.

KEYWORDS: LoRa Wireless Technology, WSN Technology, Smart Agriculture system

Copyright (c) 2014-2020 International Journal for Modern Trends in Science and Technology . All rights reserved. DOI: https://doi.org/10.46501/IJMTST060503

\section{INTRODUCTION}

The demand for food supply is increasing due to an increase in the global population [6]. IoT (Internet of Things) tends to develop certain techniques in the field of agriculture to increase food production, and farmers can also get useful information regarding to the moisture and soil requirements, etc. IoT sensors are also capable of providing information on agriculture fields. The agriculture system makes use of a WSN (Wireless sensor network) that assembles data from sensors, deployed at distinct nodes and forwards it over the wireless protocol like Wi-Fi, Bluetooth, Zigbee, LoRa (Long Range).

We already have a handful of wireless protocols like BLE (Bluetooth low energy), Wi-Fi, and
Cellular, etc [1]. But these technologies are not ideal for IoT sensor nodes, because they required the transmit information to a long distance without using much power and also with low cost [1]. That's why we are using LoRa Technology.

The term LoRa stands for Long Range. It is a wireless radio frequency technology introduced by Semtech [1]. Lora is used to transmitting information in both directions (Bi-directional) to long-distance and typically LoRa can achieve a distance of 15 to $20 \mathrm{~km}$ and can work on battery for a year [1].

In wireless technology solutions, BLE works with low power, but cannot send data to long-distance [1]. Where radio frequency can send data to long 
distance but requires more power supply [1]. So this is what brings in the need for LoRa [1]. Using LoRa we can achieve high distance communication, thus it overcomes the drawbacks of Wi-Fi and BLE communication. The below chart provides a difference between WSN technology.

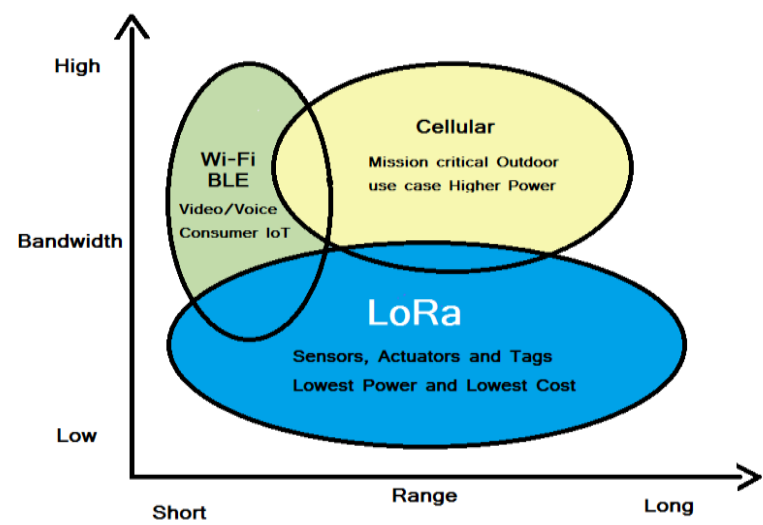

Figure 1: WSN Comparison Graph [1][2]. Table 1: WSN Comparison Table[3]

\begin{tabular}{|c|c|c|c|}
\hline $\begin{array}{c}\text { Wireless } \\
\text { Technology }\end{array}$ & $\begin{array}{c}\text { Wireless } \\
\text { Communication }\end{array}$ & Range & $\begin{array}{c}\text { Tx } \\
\text { Power }\end{array}$ \\
\hline Bluetooth & Short range & $\sim 10$ & $\sim 2.5$ \\
\hline Wi-Fi & Short range & $\sim 50$ & $\sim 80$ \\
\hline $3 \mathrm{G} / 4 \mathrm{G}$ & Cellular & $\sim 5000$ & $\sim 500$ \\
\hline \multirow{6}{*}{ LoRa } & \multirow{6}{*}{ LPWAN } & $2000-5000$ & \multirow{6}{*}{$\sim 20$} \\
\hline & & (Urban area) & \\
\hline & & $5000-15000$ & \\
\hline & & (Rural area) & \\
\hline & & $>15000$ & \\
\hline & & $\begin{array}{c}\text { (Direct Line } \\
\text { of Sight) }\end{array}$ & \\
\hline
\end{tabular}

The above table provides a better understanding of a WSN.

\section{WSN TECHNOLOGY}

As discussed, nowadays in precision agriculture, a WSN bring a cost-effective solution to watch and manipulate. It also eliminates the need for hardwire sensor stations across the field and reduces installation and maintenance costs [10].

Y. Kim, et al. [10] designed remote sensing and control of an irrigation system using a distributed wireless sensor network. In this proposed system [10], communication signals from the sensor network and irrigation controller to the base station were successfully interfaced using low-cost Bluetooth wireless radio receiver [10]. They also developed graphical user interface-based software [10]. Wireless data communication was well described by Y. Kim, et al. [10] in which, Bluetooth module was selected for the wireless data communication from the in-field sensing station to a base station.

Table 2: Survey Table

\begin{tabular}{|c|c|c|c|c|}
\hline No. & $\begin{array}{c}\text { Paper } \\
\text { Title }\end{array}$ & $\begin{array}{c}\text { Author } \\
\text { name }\end{array}$ & Module used & Advantages \\
\hline 1. & $\begin{array}{l}\text { IOT Based } \\
\text { Smart Crop } \\
\text { field } \\
\text { Monitoring } \\
\text { and } \\
\text { Automation } \\
\text { Irrigation } \\
\text { System }\end{array}$ & $\begin{array}{l}\text { R. Nageswara } \\
\text { Rao, } \\
\text { B.Sridhar }\end{array}$ & $\begin{array}{l}\text { Raspberry PI, } \\
\text { Soil moisture } \\
\text { sensor, } \\
\text { Temperature } \\
\text { Sensor, Relay } \\
\text { (For controlling } \\
\text { AC Motor), } \\
\text { Buzzer, } \\
\text { MCP3208 } \\
\text { (Convert } \\
\text { Analog to } \\
\text { Digital Signals) }\end{array}$ & $\begin{array}{l}\text { Crop } \\
\text { development at } \\
\text { low quantity } \\
\text { water } \\
\text { consumption } \\
\text { [4]. }\end{array}$ \\
\hline 2. & $\begin{array}{l}\text { IOT Based } \\
\text { Smart } \\
\text { Agriculture } \\
\text { System }\end{array}$ & $\begin{array}{l}\text { G. Sushanth1 } \\
\text { and S. } \\
\text { Sujatha2 }\end{array}$ & $\begin{array}{l}\text { Arduino, } \\
\text { Moisture, } \\
\text { Humidity, } \\
\text { Temperature, } \\
\text { and Motion } \\
\text { Sensors, Relay, } \\
\text { Water pump, } \\
\text { GSM/GPRS, } \\
\text { LCD Display, } \\
\text { Power Supply. }\end{array}$ & $\begin{array}{l}\text { Send suggestion } \\
\text { via SMS to the } \\
\text { farmer directly } \\
\text { on his mobile } \\
\text { using GSM } \\
\text { module instead } \\
\text { of mobile } \\
\text { app[5]. }\end{array}$ \\
\hline 3. & $\begin{array}{l}\text { IOT Based } \\
\text { Intelligent } \\
\text { Agriculture } \\
\text { Field } \\
\text { Monitoring } \\
\text { System }\end{array}$ & $\begin{array}{l}\text { Md } \\
\text { Ashifuddn } \\
\text { Mondal, } \\
\text { Zeenat } \\
\text { Rehena }\end{array}$ & $\begin{array}{l}\text { Temperature } \\
\text { sensor, soil } \\
\text { moisture sensor, } \\
\text { Arduino UNO, } \\
\text { NodeMCU }\end{array}$ & $\begin{array}{l}\text { The level of } \\
\text { water content in } \\
\text { a land is low the } \\
\text { pump gets ON } \\
\text { automatically or } \\
\text { the level of } \\
\text { water content in } \\
\text { a land is high } \\
\text { the pump gets } \\
\text { OFF } \\
\text { automatically } \\
\text { [6]. }\end{array}$ \\
\hline 4. & $\begin{array}{l}\text { Developme } \\
\text { nt of WSN } \\
\text { System for } \\
\text { precision } \\
\text { Agriculture } \\
\text {. }\end{array}$ & $\begin{array}{l}\text { Santosh } \\
\text { kumar, } \\
\text { Udaykumar } \\
\text { R.Y }\end{array}$ & $\begin{array}{l}\text { Arduino UNO, } \\
\text { Temperature } \\
\text { sensor, } \\
\text { Humidity } \\
\text { sensor, Zigbee } \\
\text { Radio }\end{array}$ & $\begin{array}{l}\text { WSN provides a } \\
\text { simple cost } \\
\text { effective } \\
\text { solution to } \\
\text { monitor and } \\
\text { control. } \\
\text { ZIGBEE } \\
\text { technology is } \\
\text { used as } \\
\text { WSN[7]. }\end{array}$ \\
\hline 5. & $\begin{array}{l}\text { IOT } \\
\text { agriculture } \\
\text { system } \\
\text { based on } \\
\text { LoRaWAN }\end{array}$ & $\begin{array}{l}\text { Danco } \\
\text { Davcev, } \\
\text { Kosta } \\
\text { Mitreski, } \\
\text { Stefan } \\
\text { Trajkovic, } \\
\text { Viktor } \\
\text { Nikolovski, } \\
\text { Nikola Koteli }\end{array}$ & $\begin{array}{l}\text { Microcontroller, } \\
\text { Sensors, Lora } \\
\text { WAN }\end{array}$ & $\begin{array}{l}\text { This system } \\
\text { base on Lora } \\
\text { WAN network } \\
\text { for long range } \\
\text { and low power } \\
\text { consumption } \\
\text { data } \\
\text { transmission } \\
\text { from sensor } \\
\text { nodes to the } \\
\text { cloud } \\
\text { service[9]. }\end{array}$ \\
\hline
\end{tabular}


The key features of Bluetooth technology are low power, low cost, and communication between Bluetooth device follows a strict master-slave scheme [10]. Y. Kim [10] observed Bluetooth radio transmission at a downloading interval of $15 \mathrm{~min}$, daily total power consumption was $23.8 \mathrm{Wh}$ [10].

A. Hanggoro, et al. [11] proposed and designed a greenhouse monitoring and controlling using an android mobile application, which was a complete system designed to monitor and control the humidity inside a greenhouse. It used an android mobile phone, connected using Wi-Fi to a central server which connects via serial communication to a microcontroller and humidity sensor. According to them, Wi-Fi has been implemented all over the world, and $802.11 \mathrm{~g}$ was the third modulation standard for wireless LANs. It worked in the 2.4 $\mathrm{GHz}$ band (like 802.11b) but operated at a maximum raw data rate of $54 \mathrm{Mbit} / \mathrm{s}$, or about 19 $\mathrm{Mbit} / \mathrm{s}$ net throughputs. It used wireless $\mathrm{G}$ for communication path from android to server and vice versa. A. Hanggoro, et al. [11], in their paper, the hardware system was divided into 3 parts which are microcontroller Arduino, a sensor, and IEEE wireless $802.11 \mathrm{~g}$. Microcontroller send the value from the sensor to the android via computer through serial communication and wireless connection [11].

Santoshkumar, et al. [7] in their research, select various sensors and methods for precision agriculture such as temperature sensor, humidity sensor, and Arduino (ATMega328) microcontroller board with the wireless sensor network system. The role of WSN is to sense the remote data from the desired location and transmit through the wireless network which can be viewed by the receiver. The earlier monitoring systems had a lot of limitations such as distance and reliability factors. Previously, wireless network used RF technology which was replaced by Bluetooth technology, and Bluetooth has replaced by ZIGBEE technology [7].

Santoshkumar, et al. [7] discusses the development of WSN system for precision agriculture based on the ZIGBEE wireless sensor network. ZIGBEE is a specification for wireless personal area networks (WPANs), and operating at $868 \mathrm{MHz}, 902-928 \mathrm{MHz}$, and $2.4 \mathrm{GHz}$ [7]. Moreover, WPAN is a personal area network in which the device connection is wireless. The ZIGBEE is used as LR-WPAN i.e. low rate wireless personal area network. According to them, using ZIGBEE devices in a WPAN can communicate at speeds up to $250 \mathrm{Kbps}$ while physically separated by distances up to 50 meters in typical circumstances and greater distances in an ideal environment [7].

M. Dholu, et al. [8] proposed and designed an IoT for precision agriculture application. This proposed system consists of various components like humidity \& temperature sensor, soil moisture sensor, and microcontroller unit (MCU) along with Wi-Fi module, using Wi-Fi router uploaded the sensed data on Thingspeak [16] cloud and finally displayed it on the mobile application. According to them, soil moisture measurement has done by using the YL - 69 electrodes. There is two terminal in electrode between which the resistance is measured. With a change in the soil moisture the resistance between these two-point changes. So this change in moisture is the measure of the amount of moisture in the soil. YL-38 is a chip which is used in the proposed work to convert the change in resistance into an analog voltage, it is fed with $3.3 \mathrm{v}$ supply so it gives an output from 0 to 3.3 v. Output of this chip is fed to MCU unit. NodeMCU is a microcontroller unit that is used as an MCU, which is development prototyping kit based on ESP8266.

P. Gangurde, et al. [12] designed a novel approach for precision agriculture using a wireless sensor network. In their research, they propose different topologies for precision agriculture. The development and deployment of WSNs have taken traditional network topologies in new directions [12]. Different WSN topologies are Bus, Star, Ring, and Grid [12]. According to them, delay in star case was much less than the delay in a bus, grid, and ring topology [12]. As per their research, average network delay using the execution for the four cases was $45 \mathrm{~ms}$ for the star, $71 \mathrm{~ms}$ for the grid, $81 \mathrm{~ms}$ for the bus and $98 \mathrm{~ms}$ for the ring topology [8]. In star topology, the delay was decreased by approximately $50 \%$. [12].

D. I. Sacaleanu, et al. [13] discussed a data compression on the wireless sensor nodes lifetime for LoRa technology, comparing with ZigBee and Enhanced ShockBurst.

According to D. I. Sacaleanu, et al. [13] DASMote node with ZigBee protocol acquires 7 parameters and transmits 14 data bytes without data compression. The average current recorded in the transmission was $27 \mathrm{~mA}$, while the current spend on $58.45 \mathrm{~ms}$ transmission timeframe was $1.59 \mathrm{~mA}$, thus resulting in a $\sim 20 \%$ energy improvement [13]. 
For the Arduino nodes with the Enhanced ShockBurst protocol, there were acquired 7 parameters and transmit 14 bytes without data compression, 2 bytes for each parameter [13]. The average current in the transmission was $6 \mathrm{~mA}$ [13], while the current spend on a $4.64 \mathrm{~ms}$ timeframe was $28.1 \mu \mathrm{A}$, thus resulting in a $\sim 7 \%$ energy improvement [13]. And the LoPy node with LoRa acquires also 7 parameters and transmits 14 data bytes without data compression [13]. The average current in the transmission was $154 \mathrm{~mA}$, while the current spend on an $1190 \mathrm{~ms}$ timeframe was 183 $\mathrm{mA}$, thus resulting in a $\sim 31 \%$ energy improvement [13].

D. Davcev, et al. [9] developed an IoT agriculture system based on LoRaWAN. As discussed, RF technology was replaced by Bluetooth technology, and Bluetooth was replaced by ZIGBEE technology, And ZIGBEE has replaced by LoRa technology.

D. Davcev, et al. [9] in their paper, discussed LoRa technology. Use LoRaWAN and LPWAN (Low-power Wide-Area Network) as a transmission protocol that was designed by the LoRa Alliance and met the need of the IoT services [9]. LoRaWAN network was specifically designed for IoT applications with the purpose of connecting thousands of sensors, modules, and appliances over a large network [9]. LoRa is the physical layer of the LoRaWAN which is based on CSS (Chirp Spread Spectrum) modulation, which maintains the same low power characteristics as FSK modulation but significantly increases the communication range [9].

According to D. Davcev, et al. [9], LoRaWAN can achieve data transmission range from $2-5 \mathrm{~km}$ in urban areas and to $15 \mathrm{~km}$ in suburban areas, LoRaWAN's star of stars topology in comparison with ZigBee's mesh network topology does not need additional modules to act as routers, which decreases the overall cost and complexity of the network [9].

\section{LORA TECHNOLOGY}

In this section, the basic concepts of LoRaWAN, LPWAN, and LoRa technologies will be described.

Figure 2, characterizes typical parts and architecture of an LPWAN network. The LPWAN sensors, or an end node, collect different measured values and using LoRaWAN send the data to the gateway. The gateway transmits the data to some internet cloud service. The client can use that collected data from cloud services.

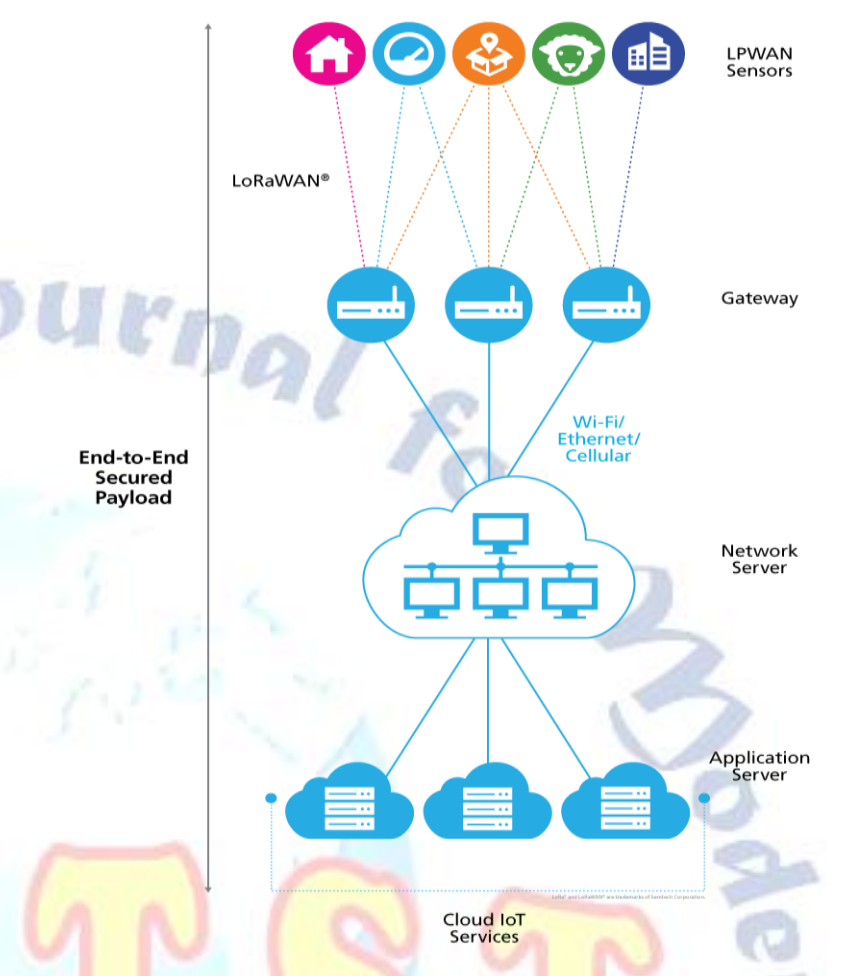

Figure 2: Communication protocol and system architecture of LoRaWAN [1][14].

The advantage of LoRa lies in technology's long-range capability. A single base station can cover hundreds of square kilometers, but the range is highly dependent on the environment or obstructions [15]. The LoRa modulation can be utilized by many different protocol architectures such as Star, and Mesh.

LoRaWAN ensures data rates from $0.3 \mathrm{kbps}$ up to $50 \mathrm{kbps}$, which are considered acceptable for transmitting real-time sensor data in the IoT [15]. The bandwidth of LoRa is low, nonetheless, transmitting anything that requires high bandwidth, or transmission of real-time image data, that may not suitable on the LoRa network.

LoRaWAN defines three classes of devices. These device classes can negotiate network downlink communication latency versus the battery lifetime [15]. These classes are shown in Fig. 3 and, depending on the application needs, A, B, or C class can be chosen.

Battery-powered devices in "Class A" are intended for low powered devices such as sensors, these are the most energy-efficient class but have the biggest latency time [15]. It also includes devices that do not need to transmit data all the 
time. All the LoRaWAN-capable devices must support the functionalities of this class [15].

Class B is focused on battery-powered devices such as sensors. These are energy efficient but with a latency controlled downlink. And the $\mathrm{C}$ class is used by bi-directional (both direction) with maximal receive slots, which has almost continuously open receive windows, which are only closed when transmitting [15].

\begin{tabular}{|c|c|c|c|c|}
\hline \multicolumn{5}{|c|}{ Application } \\
\hline \multicolumn{5}{|c|}{ LoRa MAC } \\
\hline \multicolumn{5}{|c|}{ MAC options } \\
\hline \multicolumn{2}{|c|}{$\begin{array}{c}\text { Class A } \\
\text { (Baseline) }\end{array}$} & $\begin{array}{c}\text { Class B } \\
\text { (Baselin }\end{array}$ & & $\begin{array}{c}\text { Class C } \\
\text { (Baseline) }\end{array}$ \\
\hline \multicolumn{5}{|c|}{ LoRa Modulation } \\
\hline \multicolumn{5}{|c|}{ Regional ISM band } \\
\hline EU 868 & EU 433 & US 915 & AS 430 & - \\
\hline
\end{tabular}

Figure 3: The communication protocol and system architecture of LoRaWAN [14][15].

LoRaWAN network protocol security is based on IEEE 802.15 .4 and is also extended by using two session keys: a network session key and an application session key. Each LoRaWAN edge node device also has its own 128-bit AES key, known as the AppKey [15].

\section{SURVEY OF EXISTING WORKFLOW}

Santoshkumar, et al. [7] discussed the development of the WSN system for precision agriculture based on the ZIGBEE wireless sensor network.

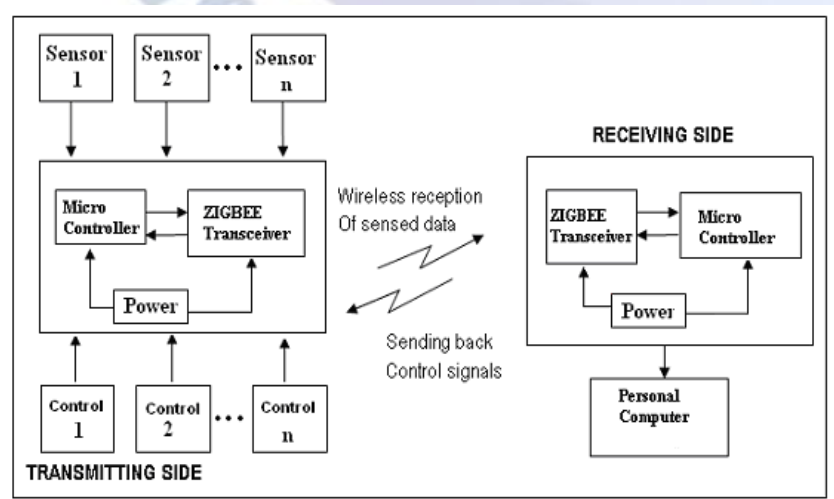

Figure 4: Existing Workflow[7].

Santosh Kumar, Udaykumar R.Y proposed the WSN node using ZIGBEE. In this model, at the transmitting side, the Microcontroller and ZIGBEE transceiver was power by the external power supply. And different sensors were connected with a microcontroller, all the sensors data were controlled and collected by the microcontroller, and using the ZIGBEE transceiver transmits the sensed data wirelessly. At the receiving side, another microcontroller and the ZIGBEE transceiver were there, it will receive the sensed data and use for the personal computer.

They were using WSN as a ZIGBEE, operating at $868 \mathrm{MHz}, 902-928 \mathrm{MHz}$, and $2.4 \mathrm{GHz}$, and communicate at speeds up to $250 \mathrm{kbps}$ while physically separated by distances up to 50 meters [7].

\section{SUMMARY}

LoRa is WSN technology [14], for constituting a smart agriculture system. This paper wrap up a variety of WSN technologies such as Bluetooth, ZIGBEE, WiFi, and LoRa to implement a smart agriculture or precision agriculture system. The benefits and limitations of these methods have discussed in this paper. It also provides a comprehensive survey for different WSN techniques used in a precision agriculture system. The survey still provides detailed information about LoRa wireless technology used in smart agriculture.

\section{REFERENCES}

[1] "Arduino LoRa Tutorial: Interfacing SX1278 (Ra-02) LoRa Module with Arduino." [Online]. Available: https://circuitdigest.com/microcontroller-projects/arduin o-lora-sx1278-interfacing-tutorial. 27-Nov-2019].

[2] "lora comparison - Google Search." [Online]. Available: https://www.google.com/search?q=lora+comparison\&sxs rf=ACYBGNRa9EsJ4w1 grb5vRir4gcJdPWDABQ: 15748438 36978\&source $=1 \mathrm{nms} \& \mathrm{tbm}=\mathrm{isch} \& \mathrm{sa}=\mathrm{X} \& \mathrm{ved}=2 \mathrm{ahUKEwi6}-$ Oq7_onmAhXw7HMBHQwFBN8Q_AUoAXoECA4QAw\&biw $=1536 \& b i h=792 \#$ imgrc $=$ tC4H51VJnlB50M: [Accessed: 27-Nov-2019].

[3] LoRa/LoRaWAN tutorial 1: IoT, LPWAN, Semtech, LoRa. .

[4] R. N. Rao and B. Sridhar, "IoT based smart crop-field monitoring and automation irrigation system," in 2018 2nd International Conference on Inventive Systems and Control (ICISC), 2018, pp. 478-483, doi: 10.1109/ICISC.2018.8399118.

[5] G. Sushanth and S. Sujatha, "IOT Based Smart Agriculture System," in 2018 International Conference on Wireless Communications, Signal Processing and Networking (WiSPNET), 2018, pp. 1-4, doi: 10.1109/WiSPNET.2018.8538702.

[6] M. AshifuddinMondal and Z. Rehena, "IoT Based Intelligent Agriculture Field Monitoring System," in 2018 8th International Conference on Cloud Computing, Data Science Engineering (Confluence), 2018, pp. 625-629, doi: 10.1109/CONFLUENCE.2018.8442535. 
[7] Santoshkumar and Udaykumar R.Y, "Development of WSN system for precision agriculture," in 2015 International Conference on Innovations in Information, Embedded and Communication Systems (ICIIECS), 2015, pp. 1-5, doi: 10.1109/ICIIECS.2015.7192904.

[8] M. Dholu and K. A. Ghodinde, "Internet of Things (IoT) for Precision Agriculture Application," in 2018 2nd International Conference on Trends in Electronics and Informatics (ICOEI), 2018, pp. 339-342, doi: 10.1109/ICOEI.2018.8553720.

[9] D. Davcev, K. Mitreski, S. Trajkovic, V. Nikolovski, and N. Koteli, "IoT agriculture system based on LoRaWAN," in 2018 14th IEEE International Workshop on Factory Communication Systems (WFCS), 2018, pp. 1-4, doi: 10.1109/WFCS.2018.8402368.

[10] Y. Kim, R. G. Evans, and W. M. Iversen, "Remote Sensing and Control of an Irrigation System Using a Distributed Wireless Sensor Network," IEEE Trans. Instrum. Meas., vol. 57, no. 7, pp. 1379-1387, Jul. 2008, doi: 10.1109/TIM.2008.917198.

[11] A. Hanggoro, M. A. Putra, R. Reynaldo, and R. F. Sari, "Green house monitoring and controlling using Android mobile application," in 2013 International Conference on QiR, 2013, pp. 79-85, doi: 10.1109/QiR.2013.6632541.

[12] P. Gangurde and M. Bhende, "A Novel Approach for Precision Agriculture Using Wireless Sensor Network," p. 8, 2015.

[13] "Data Compression in Wireless Sensor Nodes with LoRa IEEE Conference Publication." [Online]. Available: https://ieeexplore.ieee.org/document/8679003. [Accessed: 09-Jan-2020].

[14] "What is LoRa? | Semtech LoRa Technology | Semtech." [Online].

https://www.semtech.com/lora/what-is-lora. [Accessed: 09-Jan-2020].

[15] "LoRa - A survey of recent research trends - IEEE Conference Publication." [Online]. Available: https://ieeexplore.ieee.org/document/8400161. [Accessed: 09-Jan-2020].

[16] IoT Analytics - ThingSpeak Internet of Things." [Online]. Available: https://thingspeak.com/. [Accessed: 03-Dec-2019].

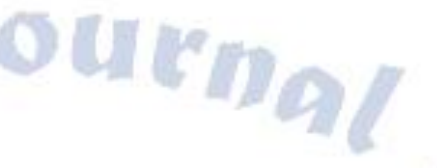

